\title{
Surveilans Pasif dan Aktif Kejadian Infeksi Terkait Pelayanan Kesehatan di RSUD Provinsi NTB, 2017
}

\author{
Passive and Active Surveillance for The Occurrence of Health-Care Associated \\ Infections at NTB Provincial Hospital, 2017
}

Eustachius Hagni Wardoyo 1,2 , Edi Prasetyo Wibowo ${ }^{2,3}$, I Gede Jayantika ${ }^{2,3}$, I Gst Alit Rai Sudiadnya ${ }^{2}$, Rolly Armand ${ }^{2}$, Fergy Desy Puspita ${ }^{2}$, Made Kartika ${ }^{2}$, Rahmaniar I Putri ${ }^{4}$, Mega Pratiwi $^{4}$, Rizky A Pratama ${ }^{4}$, Farihant Masruro ${ }^{4}$

${ }^{1}$ Departemen Mikrobiologi Fakultas Kedokteran Universitas Mataram Lombok, ${ }^{2}$ Tim Pencegahan dan Pengendalian Infeksi RSUD Provinsi NTB, Lombok, ${ }^{3}$ Departemen Kebidanan dan Kandungan RSUD Provinsi NTB, Lombok, ${ }^{4}$ Mahasiswa Fakultas Kedokteran Universitas Mataram Lombok

Korespondensi Penulis:

Eustachius Hagni Wardoyo

Email: wardoyo.eh@unram.ac.id

\begin{abstract}
Abstrak
Pendahuluan: Surveilans Health-care Associated Infections (HAls) atau kejadian infeksi terkait pelayanan kesehatan dapat dilakukan baik secara aktif maupun pasif sesuai sumber daya yang dimiliki. Penelitian ini bertujuan mengetahui insidensi dan perbandingan hasil surveilans pasif dan aktif 4 jenis HAls di RSUD Provinsi Nusa Tenggara Barat periode Januari-Oktober 2017. Empat jenis HAls tersebut adalah Ventilatorassociated Pneumonia (VAP), Catheter-associated Urinary Tract Infection (CAUTI), Central Lineassociated Blood Stream Infection (CLABSI) dan Surgical Site infection (SSI). Metode: Surveilans pasif menggunakan data sekunder dengan menelusuri rekam medis, sedangkan surveilans aktif berdasarkan laporan Tim Pencegahan dan Pengendalian Infeksi (PPI). Hasil: Tidak ada perbedaan indikator yang digunakan dalam form VAP dan CLABSI pada surveilans pasif dan aktif. Namun pada form CAUTI dan SSI tidak mencantumkan gejala infeksi dan gejala panas di lokasi infeksi pada surveilans aktif. Perbandingan hasil surveilans pasif dan aktif berturut-turut adalah VAP 24,9 dan 0 per 1.000 ventilator days, CAUTI 49 dan 12 per 1.000 catheter days, CLABSI 18 dan 9 per 1.000 central line days, serta SSI 1,9 dan $1,4 \%$. Kesimpulan: Ada perbedaan insidensi keempat jenis HAls pada surveilans pasif dan aktif, karena penggunaan metodologi yang berbeda.
\end{abstract}

Kata kunci: Surveilans, HAl's, RSUD Provinsi NTB

\begin{abstract}
Introduction: Health-care Associated Infection (HAls) surveillance can be either active or passive depending on the resources availability. The purpose of this study is to determine the incidence as well as comparison of passive and active surveillance for the occurrence of the 4 types of HAls at West Nusa Tenggara (NTB) Provincial Hospital from January to October 2017. These four types of HAls are 1) Ventilator-associated Pneumonia (VAP); 2) Catheter-associated Urinary Tract Infection 3)Central Lineassociated Blood Stream Infection (CLABSI); and 4) Surgical Site Infection (SSI). Methods: Passive surveillance using secondary data through searching medical records, whereas active surveillance based on the Infection Prevention and Control Committee (PPI) Team report. Results: There are no differences of indicators in the VAP and CLABSI forms on both active and passive surveillance. However the CAUTI and SSI forms does not include the symptoms of infection and heat at the site of infection on active surveillance. The comparison results between passive and active surveillance were VAP 24.9 and 0 per 1,000 ventilator days, CAUTI 49 and 12 per 1,000 catheter days, CLABSI 18 and 9 per 1,000 central line days, and SSI 1.9 and 1.4\%, respectively. Conclusions: Based on this study, there were different in the incidence of the 4 types of HAls on passive and active surveillance due to the methodological differences.
\end{abstract}

Keywords: Surveillance, Health-care Associated Infections, NTB Provincial Hospital. 
Pendahuluan

Surveilans aktif Health-care Associated Infections (HAls) adalah kegiatan yang secara khusus dilakukan untuk mencari kasus infeksi oleh petugas terlatih, biasanya dari Tim PPI dengan mencari data dari berbagai sumber. Surveilans HAls yang ideal menggunakan metode surveilans aktif dengan berbasis pasien, prospektif, memiliki prioritas dan menghasilkan angka kejadian infeksi sesuai standar. Metode ini paling bermanfaat untuk mengetahui adanya endemik HAls dibandingkan deteksi kejadian luar biasa. Surveilans pasif HAls dapat dilakukan oleh selain petugas PPI dengan mengumpulkan data HAls dari rekam medis atau dari data yang ada di bangsal secara langsung. ${ }^{(1)}$

Health-care Associated Infections merupakan infeksi yang terjadi pada pasien selama perawatan di rumah sakit atau fasilitas pelayanan kesehatan (fasyankes) lain dengan diagnosis masuk tidak ada infeksi dan tidak dalam masa inkubasi, termasuk infeksi yang didapat dari rumah sakit tetapi baru muncul setelah pasien pulang.

Di Amerika Serikat, angka kejadian HAls diperkirakan mencapai 721.800 kasus pada acute care settings tahun 2011. Kasus terbanyak adalah pneumonia dan infeksi luka operasi (masing-masing 157.500), penyakit saluran pencernaan (123.100), infeksi saluran kemih (93.300), infeksi aliran darah primer (71.900) dan infeksi lainnya (118.500). Sebesar 5-10\% pasien rawat inap mengalami HAls di negara-negara industri maju, sedangkan di negara berkembang dapat mencapai 2-20 kali lebih tinggi. Perbedaan ini menunjukkan adanya kesenjangan kelengkapan fasilitas kesehatan, sumber daya manusia serta program pencegahan dan pengendalian infeksi. ${ }^{(2-4)}$

Pembiayaan HAls berdasarkan US annual cost on HAls pada tahun 2009, infeksi luka operasi USD 10.443-25.546 per infeksi, infeksi aliran darah primer USD 5.734-22.939, pneumonia terkait ventilator USD 11.089-25.072, dan infeksi saluran kemih terkait kateter USD 589-758, dengan pemanjangan masa rawat inap berkisar antara 4,3-20 hari. ${ }^{(5)}$

Di Indonesia, kejadian HAls (infeksi nosokomial) di $10 \mathrm{RSU}$ pendidikan cukup tinggi, yaitu 6-16\% dengan ratarata $9,8 \%$ pada tahun 2010 . Infeksi yang paling umum terjadi adalah Infeksi Luka Operasi (ILO). Hasil penelitian Nugraheni R, dkk di rumah sakit di Indonesia menunjukkan bahwa angka kejadian ILO bervariasi antara 2-18\% dari keseluruhan prosedur pembedahan. ${ }^{(6)}$ 
Pencegahan dan Pengendalian Infeksi (PPI) di rumah sakit atau fasyankes merupakan suatu upaya kolektif yang melibatkan pasien, petugas, dan pengunjung untuk meminimalkan atau mencegah terjadinya penularan infeksi terutama HAls pada pasien, petugas, pengunjung, dan masyarakat sekitar rumah sakit. ${ }^{(3)}$

Upaya PPI yang efektif hanya dapat dicapai dengan pengukuran risiko infeksi yang spesifik. Salah satu kegiatan pengukuran risiko tersebut yaitu dengan melakukan surveilans. Berdasarkan Permenkes No. 27 Tahun 2017, surveilans HAls merupakan suatu proses yang dinamis, sistematis, terus menerus dalam pengumpulan, identifikasi, analisis dan interpretasi data kesehatan yang penting di fasilitas pelayanan kesehatan pada suatu populasi spesifik dan didiseminasikan secara berkala kepada pihak-pihak yang memerlukan untuk digunakan dalam perencanaan, penerapan, serta evaluasi suatu tindakan yang berhubungan dengan kesehatan. ${ }^{(7)}$

Surveilans pasif pada penelitain ini adalah pengumpulan data dari rekam medis secara retrospektif oleh peneliti setelah pelaksanaan surveilans aktif, sedangkan surveilans aktif dilakukan Infection Prevention and Control Link Nurse (IPCLN) dan Infection Preventif and Control Nurse (IPCN) secara prospetif. ${ }^{(8)}$ Tujuan penelitian adalah untuk mengetahui insidensi 4 jenis HAls serta mendeskripsikan perbandingan hasil surveilans pasif dan aktif kejadian HAls di RSUD Provinsi NTB. Keempat jenis HAls tersebut adalah 1) Ventilator-associated Pneumonia (VAP); 2) Catheterassociated Urinary Tract Infection (CAUTI); 3): Central Line-associated Blood Stream Infection (CLABSI); dan 4) Surgical Site Infection (SSI).

\section{Metode}

Surveilans pasif menggunakan data sekunder dengan melakukan penelusuran data rekam medis periode Januari-September 2017, sedangkan surveilans aktif berdasarkan laporan Tim PPI. Alur seleksi pada penelitian ini menggunakan informasi buku register pasien di semua bangsal perawatan dengan kriteria inklusi dan eksklusi penelitian sesuai jenis HAls (Tabel 1 ).

Form surveilans pasif dikembangkan menggunakan kriteria CDC's National Healthcare Safety Network (CDC/NHSN) tahun 2008. ${ }^{(8)}$ Surveilans aktif menggunakan form surveilans Tim PPI. Setelah keseluruhan data HAls diperoleh, maka dari kedua jenis surveilans dilakukan analisis dan perbandingan hasil. 
Tabel 1. Kriteria inklusi dan eksklusi penelitian (VAP: Ventilator-associated Pneumonia; CAUTI: Catheter-associated Urinary Tract Infection; CLABSI: Central Lineassociated Blood Stream Infection; SSI: Surgical Site Infection; CVC: Central Venous Catheter)

\begin{tabular}{|c|c|}
\hline Jenis HAls & Kriteria Inklusi dan Eksklusi \\
\hline VAP & $\begin{array}{l}\text { Kriteria inklusi } \\
\text { 1) Data rekam medis pasien terpasang ventilator mekanik yang dirawat } \geq \\
48 \text { jam } \\
\text { 2) Data rekam medis pasien dengan demam }\left(>38^{\circ} \mathrm{C}\right) \text { tanpa sebab yang } \\
\text { jelas } \\
\text { 3) Data rekam medis pasien dengan leukopenia }\left(<4000 / \mathrm{mm}^{3}\right) \text { atau } \\
\text { leukositosis }\left(\geq 12.000 / \mathrm{mm}^{3}\right) \\
\text { Kriteria eksklusi } \\
\text { 1) Data rekam medis pasien dengan diagnosis pneumonia sebelum } \\
\text { pemasangan ventilator } \\
\text { 2) Pasien yang terpasang ventilator namun rekam medis tidak ditemukan }\end{array}$ \\
\hline CAUTI & $\begin{array}{l}\text { Kriteria inklusi } \\
\text { 1) Terpasang kateter yang dirawat } \geq 48 \text { jam } \\
\text { 2) Demam }\left(>38^{\circ} \mathrm{C}\right) \text {. Demam merupakan salah satu gejala dalam } \\
\text { penegakkan terjadinya infeksi, yang dicatat oleh peneliti sebagai faktor } \\
\text { risiko terjadinya CAUTI/ISK HAls) } \\
\text { 3) Leukositosis }(\geq 12.000 \mathrm{WBC} / \mathrm{mm} 3) \\
\text { 4) Tidak mengalami infeksi lain sebelum dan /atau saat masuk rumah } \\
\text { sakit } \\
\text { Kriteria eksklusi } \\
\text { 1) Rekam medis tidak ditemukan } \\
\text { 2) Rekam medis tidak memiliki kelengkapan data }\end{array}$ \\
\hline $\mathrm{CLAE}$ & $\begin{array}{l}\text { Kriteria inklusi } \\
\text { 1) Data rekam medis yang terpasang } \mathrm{CVC} \text { yang dirawat } \geq 48 \text { jam di ICU } \\
\text { 2) Data rekam medis pasien dengan demam }\left(>38^{\circ} \mathrm{C}\right) \text { tanpa sebab yang } \\
\text { jelas sesudah pemasangan } \mathrm{CVC} \\
\text { 3) Data rekam medis pasien dengan leukopenia }(<4000 \mathrm{WBC} / \mathrm{mm} 3) \text { atau } \\
\text { leukositosis }(\geq 12.000 \mathrm{WBC} / \mathrm{mm} 3) \text { sesudah pemasangan } \mathrm{CVC} \\
\text { 4) Data rekam medis pasien dengan infeksi/sepsis sesudah pemasangan } \\
\mathrm{CVC} \\
\text { 5) Tidak mengalami infeksi lain sebelum dan /atau saat masuk-rumah } \\
\text { sakit } \\
\text { Kriteria eksklusi } \\
\text { 1) Mengalami infeksi lain sebelum dan /atau pada saat masuk rumah sakit } \\
\text { 2) Pasien yang terpasang CVC namun data rekam medis tidak ditemukan }\end{array}$ \\
\hline SSI & $\begin{array}{l}\text { Kriteria inklusi } \\
\text { 1) Pasien pasca operasi yang dirawat } \geq 48 \text { jam. } \\
\text { 2) Tidak mengalami infeksi sebelum masuk rumah sakit. } \\
\text { 3) Pasien melakukan kontrol pasca operasi ke Poliklinik Bedah/ } \\
\text { Kandungan dan kebidanan } \\
\text { Kriteria eksklusi } \\
\text { 1) Pasien pasca operasi yang tidak menunjukkan tanda-tanda infeksi } \\
\text { 2) Rekam medis pasien tidak ditemukan } \\
\text { 3) Partus lama }\end{array}$ \\
\hline
\end{tabular}

\section{Hasil}

Tidak ada perbedaan indikator yang digunakan dalam form surveilans VAP, baik pasif (CDC/NHSN) maupun aktif
(PPI). Hal ini mengindikasikan bahwa form surveilans Tim PPI sudah menggunakan kriteria $\mathrm{CDC} / \mathrm{NHSN}$ (Tabel 2). 
Tabel 2. Indikator dalam form surveilans VAP pasif dan aktif ( $V$ : Tercantum; (-): Tidak tercantum)

\begin{tabular}{lcc}
\hline \multicolumn{1}{c}{ Indikator VAP } & PPI & CDC/NHSN, 2008 \\
\hline Pemakaian ventilasi mekanik $>48$ jam & $\sqrt{ }$ & $\sqrt{ }$ \\
Demam $>38^{\circ}$ C & $\sqrt{ }$ & $\sqrt{ }$ \\
Sputum purulen & $\sqrt{ }$ & $\sqrt{ }$ \\
Sesak napas & $\sqrt{ }$ & $\sqrt{ }$ \\
Ronki basah & $\sqrt{ }$ & $\sqrt{ }$ \\
Foto toraks terdapat infiltrat baru & $\sqrt{ }$ & $\sqrt{ }$ \\
Leukositosis (sel darah putih $>12.000 / \mathrm{mm}^{3}$ & $\sqrt{ }$ & $\sqrt{ }$ \\
Leukopenia (sel darah putih $<4.000 / \mathrm{mm}^{3}$ ) & $\sqrt{ }$ & \\
\hline
\end{tabular}

Sebanyak 31 subyek VAP memenuhi kriteria inklusi dengan usia 16 sampai 72 tahun dan rerata 47 tahun. Sebagian besar berusia $<65$ tahun $(87,1 \% ; 27 / 31)$, diikuti $\geq 65$ tahun (12,9\%; 4/31). Pada umumnya laki-laki (58,1\%; 18/31), kemudain perempuan (41,9\%; 13/31). Durasi pemasangan ventilator 1.243 hari. Pemeriksaan kultur dilakukan terhadap 9 kasus dengan hasil Klebsiella pneumoniae (44,4\%; 4/9), Pseudomonas aeruginosa dan Staphylococcus aureus (masingmasing 22,2\%; 2/9), serta Serratia marcescens (11,1\%; 1/9). Sebanyak 3 kasus $(9,7 \% ; 3 / 31)$ mengalami komplikasi pneumonia, dan 1 (3,2\%; 1/31) unweaningable ventilator (Tabel $3)$.

Tabel 3. Karakteristik subyek VAP (MDRO: Multidrugs Resistant Organism)

\begin{tabular}{lcl}
\hline \multicolumn{1}{c}{ Karakteristik subyak penelitian } & $\mathbf{n}(\%)$ & \multicolumn{1}{c}{ Keterangan } \\
\hline Usia (tahun) & $27(87,1)$ & \\
$\quad<65$ & $4(12,9)$ & \\
$\geq 65$ & $18(58,1)$ & \\
Jenis kelamin & $13(41,9)$ & \\
Laki-laki & 1.243 & \\
$\quad$ Perempuan & $4(44,4)$ & Klebsiella pneumoniae \\
Durasi pemasangan ventilator (hari) & \\
Hasil kultur sputum (n=9) & $2(22,2)$ & MDRO Pseudomonas aeruginosa \\
& $2(22,2)$ & MDRO Staphylococcus aureus \\
& $1(11,1)$ & MDRO Serratia marcescens \\
Komplikasi & $3(9,7)$ & Pneumonia \\
& $1(3,2)$ & Unweaningable ventilator \\
\hline
\end{tabular}

Indikator dalam form CAUTI pasif (CDC/NHSN. 2008) terdiri dari: 1) Lama pemasangan; 2) Memiliki 1 atau lebih gejala/tanda infeksi (demam $>38^{\circ} \mathrm{C}$, nyeri suprapubik, frekuensi berkemih, nyeri kepala, nyeri tekan pada kostovertebra, urgensi berkemih, disuria; dan 3) Kultur urin dengan tidak lebih dari 2 spesies mikroorganisme yang teridentifikasi, setidaknya satu diantaranya adalah bakteri $\geq 10^{5}$ CFU/ml. Form CAUTI pada surveilan 
aktif (PPI) tidak mencantumkan gejala/tanda infeksi. Sebanyak 50 subyek memenuhi kriteria inklusi CAUTI. Sebagian besar berusia $>40$ tahun (72\%; 36/50) dimana 14 orang diantaranya $\geq 60$ tahun, diikuti $\leq 40$ tahun (28\%; 14/50). Pada umumnya (60\%; 30/50) perempuan, dan $(40 \%$; 20/50) laki-laki. Durasi pemasangan kateter 1.020 hari.

Tidak ada perbedaan indikator dalam form CLABSI pada surveilans pasif (CDC/NHSN, 2008) dan aktif (PPI). Indilator meliputi: 1) Lama pemasangan, WBC (<4000 WBC/mm3) atau ( $\geq 12.000 \mathrm{WBC} / \mathrm{mm} 3)$, 2) Demam $>38^{\circ} \mathrm{C}$; 3) Jenis/jalur pemasangan; 4) Lokasi pemasangan; 5) Teknik pemasangan; 5) Perawatan; 6) Kondisi pasien; dan 7) Hasil kultur. Sebanyak 22 subyek CLABSI memenuhi kriteria inklusi, usia 22-77 tahun dengan rerata 44 tahun. Sebagian besar (90,9\%; 20/22) berusia $\geq 40$ tahun, diikuti $<40$ tahun $(9,1 \% ; 2 / 22)$. Sebagian besar laki-laki $(59,1 \% ; 13 / 22)$, kemudian perempuan (40,9\%; 9/22). Lama pemasangan ventilator 1.220 hari.

Indikator dalam form SSI meliputi: 1) Pus; 2) Kemerahan; 3) Nyeri; 4) Bengkak; 5) Tanggal operasi; 6) Panas pada lokasi infeksi; dan 7) Demam. Ada perbedaan indikator dalam form SSI pada surveilans pasif dan aktif, dimana gejala panas pada lokasi infeksi tidak tercantum pada surveilans aktif (PPI) (Tabel 4).

Tabel 4. Indikator dalam form SSI pada surveilans pasif dan aktif

\begin{tabular}{lcc}
\hline \multicolumn{1}{c}{ Indikator dalam form SSI } & CDC/NHSN, 2008 & PPI \\
\hline Pus & $\sqrt{ }$ & $\sqrt{ }$ \\
Kemerahan & $\sqrt{ }$ & $\sqrt{ }$ \\
Nyeri & $\sqrt{ }$ & $\sqrt{ }$ \\
Bengkak & $\sqrt{ }$ & $\sqrt{ }$ \\
Tanggal operasi & $\sqrt{ }$ & $(-)$ \\
Panas pada lokasi infeksi & $\sqrt{ }$ \\
Demam & $\sqrt{ }$ & $\sqrt{ }$ \\
\hline
\end{tabular}

Dari 13 subyek SSI, usia 36-66 tahun dengan rerata 41 tahun. Sebagian besar berusia $\geq 40$ tahun, perempuan, operasi kandungan dan kebidanan (masing-masing 92,3\%; 12/13), kemudian berturut-turut diikuti usia $<40$ tahun, laki-laki, dan operasi ortopedi (masing-masing 7,7\%; 1/13).
Perbandingan hasil surveilans pasif dan aktif berturut-turut adalah VAP 24,9 dan 0 per 1.000 ventilator days, CAUTI 49 dan 12 per 1.000 catheter days, CLABSI 18 dan 9 per 1.000 central line days, serta SSI 1,9 dan 1,4\% (Tabel 5). 
Tabel 5. Angka insidensi HAls berdasarkan hasil surveilans secara pasif dan aktif

\begin{tabular}{lll}
\hline HAIs & Surveilans pasif & Surveilans aktif \\
\hline VAP & 24,9 per 1.000 ventilator days & 0 \\
CAUTI & 49 per 1.000 catheter days & 12 per 1.000 catheter days \\
CLABSI & 18 per 1.000 central line days & 9 per 1.000 central line days \\
SSI & $1,9 \%$ & $1,4 \%$ \\
\hline
\end{tabular}

\section{Pembahasan}

Sudah menjadi pemahaman bersama bahwa surveilans HAls penting dalam mengukur kemampuan pelayanan kesehatan dalam mencegah dan mengendalikan HAls. Kebanyakan ahli penyakit infeksi, epidemiolog, dan ahli lainnya dalam bidang pencegahan dan pengendalian infeksi percaya bahwa mayoritas kasus HAls under reported. Pemilihan jenis surveilans yang dapat menghasilkan data akurat masih menjadi perdebatan hingga saat ini, karena masing-masing memiliki kelebihan dan kekurangan. Namun demikian, yang menjadi titik temu dalam pemilihan metode surveilans HAls adalah pentingnya konsistensi dalam penggunaan metode surveilans yang feasible secara terus menerus di fasyankes, sehingga dapat menghasilkan data yang memadai dalam memprediksi trend HAls dan digunakan dalam perencanaan, pelaksanaan, dan penilaian program pencegahan dan pengendalian HAls. ${ }^{(1,10,11)}$

Kelebihan surveilans pasif adalah: 1 ) Dapat mendeteksi kasus yang lebih sensitif atau kasus yang tidak terdeteksi pada surveilans aktif; 2) Memberikan cukup waktu dalam penegakkan diagnosis HAls yang lebih baik; dan 3) Cukup murah untuk dilakukan. Kekurangan surveilans pasif: 1) Tidak mampu mendeksi kasus pada kejadian luar biasa; dan 2) Tidak dapat mendeteksi population at risk penularan HAls. ${ }^{(1,11,12)}$

Kelebihan surveilans aktif: 1) Dapat digunakan untuk tugas rutin yang ringan dengan memberlakukan form surveilans yang mudah dan praktis; 2) Dapat dilakukan secara prospektif, sehingga temuan dapat segera ditindaklanjuti seperti perlu tidaknya ruang isolasi atau program intervensi yang sesuai; dan 3) Mampu mendeteksi population at risk penularan HAls. Sedangkan kekurangan surveilans aktif: 1) Memerlukan petugas surveilans yang terampil, karena meningkatkan risiko terjadinya under reported atau sebaliknya bila dilakukan oleh petugas yang tidak terampil; 2) Memerlukan pembiayaan yang cukup tinggi; dan 3) Memerlukan keterampilan dalam melaksanakan supervisi dan analisis data. ${ }^{(1,11,12)}$ 
Sampai saat ini surveilans aktif yang dilakukan Infection Prevention and Control Link Nurse (IPCLN) masih dianggap beban tambahan, hal ini wajar karena surveilans aktif yang dilakukan masih secara manual menggunakan form surveilans (paperbased).

Pada kasus VAP, meskipun terdapat perbedaan hasil, tidak ada perbedaan form pada surveilans aktif dan pasif. Kejadian VAP relatif lebih mudah dikenali IPCN dengan adanya gejala prominen produksi mukus bronkus dan sesak, namun kedaruratan tindakan pasien sedikit banyak mempengaruhi pola pencatatan data surveilans. Kepastian diagnosis pada saat dilakukan surveilans pasif lebih dimungkinkan, karena adanya data rekam medis yang lebih lengkap. Pengelompokan usia pada VAP menggunakan kriteria CURB-65 (confusion, BUN, respiratory rate, blood pressure, age $\geq 65$, yaitu usia $\geq 65$ dan $<65$ tahun). ${ }^{(13)}$

Pada kasus CAUTI, perbedaan temuan pada kedua jenis surveilans perlu diinvestigasi lebih lanjut. Meskipun terdapat perbedaan form CAUTI, namun dari hasil wawancara IPCLN dan IPCN, gejala dan tanda CAUTI mudah dikenali, sehingga dalam proses surveilans dapat diasumsikan tidak berbeda bila menggunakan form pada kedua jenis surveilans tersebut. Pengambilan data sekali waktu pada akhir periode, memperbesar peluang untuk menemukan lebih banyak kasus pada surveilans pasif.

Pada kasus CLABSI, gambaran bakteremia/sepsis lebih mudah ditegakkan pada saat pasien dirawat. Perbedaan hasil surveilans pasif dan aktif selain dari alasan yang sama dengan insersi benda asing lain (VAP dan CAUTI) adalah rekam medis yang dipergunakan dalam surveilans pasif selalu tidak dapat merekam onset infeksi.

Temuan pada SSI sangat menarik, karena satu-satunya HAls yang memiliki sedikit perbedaan atau hampir sama antara surveilans aktif dan pasif, hal ini dimungkinkan karena sebagian besar SSI terdiagnosis pada saat kunjungan rawat jalan pasca operasi, sehingga lebih mudah terdeteksi menggunakan form kedua jenis surveilans. Insidensi SSI pada penelitian ini sebesar $1,9 \%$, masih lebih rendah dibandingkan dengan hasil penelitian yang dilakukan di bangsal kandungan dan kebidanan RSCM tahun 2011, yaitu sebesar $4,4 \%$. $^{(14)}$

Dari keempat jenis HAls, hanya VAP yang memiliki data kultur mikrobiologi (Tabel 3). Identifikasi mikroorganisme seharusnya dilakukan meskipun terapi antibiotik empiris telah diberikan, 
terutama bakteri patogen dalam darah, cairan serebrospinal, sampel saluran respiratorik, urine kateter dan adanya kecurigaan HAls lainnya. ${ }^{(15)}$ Manfaat pemeriksaan mikrobiologis pada HAls adalah agar terapi dapat diberikan secara lebih rasional, sehingga hemat dalam penggunaan, mengurangi lama rawat inap dan risiko munculnya Multidrugs-Resistant Organisms (MDROs), serta tersedianya data epidemiologi mikroorganisme patogen sebagai dasar dalam pemberian antibiotik secara empiris di wilayah setempat.

Surveilans aktif sudah diterapkan oleh RSUD Provinsi NTB sejak tahun 2010. Kebijakan pemilihan metode ini didasarkan pada dua aspek, yaitu: 1) Memiliki infrastruktur pendukung, seperti Tim PPI dan pendanaan, dan 2) Surveilans aktif merupakan metode surveilans HAls yang saat ini digunakan dalam program nasional. RSUD Provinsi NTB merupakan RS Tipe B yang memiliki 323 tempat tidur. Tim PPI sudah terbentuk sejak 2007, saat ini beranggotakan 20 orang dengan 2 IPCD, 3 IPCN dan 15 IPCLN.

Ada perbedaan insidensi HAls pada surveilans pasif dan aktif di RSUD Provinsi NTB tahun 2017, yaitu berturut-turut adalah VAP 24,9 dan 0 per 1.000 ventilator days, CAUTI 49 dan 12 per 1.000 catheter days,
CLABSI 18 dan 9 per 1.000 central line days, serta SSI 1,9 dan 1,4\% (Tabel 5). Adanya perbedaan hasil ini, karena penggunaan metodologi yang berbeda.

\section{Kesimpulan}

Berdasarkan hasil peneitian dapat disimpulkan bawa: 1) Tidak ada perbedaan indikator yang digunakan dalam form VAP dan CLABSI pada surveilans pasif dan aktif. Namun dalam form CAUTI tidak tercantum gejala infeksi dan form SSI tanpa disertai gejala panas di lokasi infeksi pada surveilans aktif; dan 2) Ada perbedaan insidensi keempat jenis HAls pada surveilans pasif dan aktif, karena penggunaan metodologi yang berbeda. Kinerja IPCN dan IPCLN dalam pencegahan dan pengendalian infeksi tidak terungkap melalui penelitian ini.

\section{Ucapan Terima Kasih}

Ucapan terima kasih disampaikan kepada Direktur RSUD Provinsi NTB (dr. H. Lalu Hamzi Fikri, MM) beserta jajarannya atas diijinkannya penelitian ini.

\section{Daftar Pustaka}

1. Center for Disease Control and Prevention. Outline For HealthcareAssociated Infections Surveillance [Internet]. Departement of Health 
and Human Service; 2006 [cited 2018 Jan 2]. p. 1-8. Available from: https://www.cdc.gov/nhsn/PDFS/O utlineForHAISurveillance.pdf

2. Center for Disease Control and Prevention. Healthcare-associated Infections in the United States, 2006-2016: A Story of Progress | HAI | CDC. HAI Data Report. 2017.

3. Kementerian Kesehatan RI. Peraturan Menteri Kesehatan Nomor 27 Tahun 2017 tentang Pedoman Pencegahan Dan Pengendalian Infeksi Di Fasilitas Pelayanan Kesehatan. 2017;1172. Available from: http://hukor.kemkes.go.id/uploads/ produk_hukum/PMK_No._27_ttg_P edoman_Pencegahan_dan_Penge ndalian_Infeksi_di_FASYANKES_. pdf

4. Allegranzi B, Pittet D. HealthcareAssociated Infection in Developing Countries: Simple Solutions to Meet Complex Challenges [Internet]. Vol. 28, Infection Control \& Hospital Epidemiology. 2007. p. 1323-7. Available from: https://www.cambridge.org/core/pr oduct/identifier/S01959417000262 8X/type/journal_article

5. Sydnor ERM, Perl TM. Hospital epidemiology and infection control in acute-care settings. Vol. 24, Hosp Epidemiol Acute Care
Settings. 2011.

6. Nugraheni R, Tono S, Winarni S. Infeksi Nosokomial di RSUD Setjonegoro Kabupaten Wonosobo [Internet]. Vol. 11, Media Kesehatan Masyarakat Indonesia. 2012 [cited 2017 Jul 30]. p. 94100. Available from: http://ejournal. undip.ac.id/index.php/mkmi/article/ view/6169

7. Moi Lin L, Tai Yin C, Wing Hong S. Infection Control for the Asian healthcare Worker [Internet]. $3 \mathrm{rd}$. 2011 [cited 2017 Dec 22]. p. 153. Available from: http://apsicapac.org/wp-content/uploads/2016/ 09/A-Handbook-of-InfectionControl-for-the-Asian-HealthcareWorker.pdf

8. Crosby C. Monitoring Infections: Active vs. Passive Surveillance [Internet]. 2012 [cited 2018 Mar 20]. Available from: http://www. infectioncontroltoday.com/articles/2 012/04/monitoring-infectionsactive-vs-passive-surveillance.aspx

9. Horan TC, Andrus M, Dudeck MA. $\mathrm{CDC} / \mathrm{NHSN}$ surveillance definition of health care-associated infection and criteria for specific types of infections in the acute care setting. Am J Infect Control [Internet]. 2008;36(5):309-32. Available from: https://www.ajicjournal.org/article/S 0196-6553(08)00167-3/pdf 
10. Gerri H. APPROACHES TO INFECTION CONTROL _ Infection Control Today [Internet]. 2006 [cited 2012 Mar 3]. Available from: https://www.infectioncontroltoday.c om/epidemiology-surveillance/ap proaches-infection-control

11. Lee TB, Montgomery OG, Marx J, Olmsted RN, Scheckler WE. Recommended practices for surveillance: Association for Professionals in Infection Control and Epidemiology (APIC), Inc. Am J Infect Control. 2007;35(7):42740.

12. Provincial Infectious Diseases Advisory Committee. Best Practices for Surveillance of Health Care-associated Infections [Internet]. Public Health Ontario. 2014 [cited 2016 Feb 15]. p. 140. Available from: http://www. publichealthontario.ca/en/eReposit ory/Surveillance_3-3_ENGLISH
_2011-10-28 FINAL.pdf

13. Jones BE, Jones J, Bewick T, Lim WS, Aronsky D, Brown SM, et al. CURB-65 pneumonia severity assessment adapted for electronic decision support. Chest. 2011 ;140(1):156-63.

14. Wardoyo EH, Tjoa E, Ocvyanty D, Moehario LH. Infeksi Luka Operasi ( ILO ) di Bangsal Kebidanan dan Kandungan RSUPN Cipto Mangunkusumo ( RSCM ): Laporan Serial Kasus Bulan Agustus-Oktober 2011. Cdk-216. 2014;41(5):332-5.

15. François JEHL, Monique CHOMARAT, Michèle WEBER AG. From antibiogram to prescription bioMérieux Industry website [Internet]. [cited 2012 Apr 1]. Available from: https://www. biomerieux-industry. com/antibiogram-prescription 